\title{
CONFERENCIA PSICOLOGÍA DEL DESARROLLO Y EDUCACIÓN
}

\author{
Dr. Álvaro Marchesi UlLastres \\ Ceremonia de otorgamiento de la distinción de \\ Doctor Honoris Causa por la Universidad Nacional Mayor de San Marcos de Lima, Perú
}

(29 DE NOVIEMBRE DE 2012)

EXMO. SR. RECTOR dE LA UNIVERSIDAD

DIRECTORES, PROFESORES, ALUMNOS Y COMUNIDAD EDUCATIVA

Les agradezco enormemente la deferencia que han tenido conmigo al nombrarme doctor honoris causa en su centenaria universidad, decana de las Américas y una de las más reconocidas en los países iberoamericanos. Siempre me he considerado un profesor de psicología evolutiva y de la educación y así continúo firmando cuando me preguntan por mi profesión en aeropuertos y registros. Por ello, me siento aún más honrado por esta distinción ya que afecta a mi más profunda y sentida identidad profesional. He sido durante varios años Secretario de Estado de Educación en mi país y ahora ocupo el cargo de Secretario General de un organismo internacional, la OEI. Pero siempre he considerado estas responsabilidades como transitorias y al término de las mismas he vuelto y volveré a la docencia universitaria.

\section{UN ESQUEMA ORGANIZADOR}

Me piden que aporte unas reflexiones sobre las relaciones entre la Psicología del Desarrollo y la Educación. Lo haré con mucho gusto y trataré de integrar en ellas mis conocimientos científicos y mi experiencia académica pero también los aprendizajes realizados durante mis años de gestión de la educación y las opciones que he defendido en los proyectos de reforma que he impulsado.

Permítanme que les adelante cómo voy a organizar mi exposición. En primer lugar presentaré algunos apuntes sobre qué supone la psicología del desarrollo para la educación, qué aporta la educación a la psicología del desarrollo y que semejanzas y diferencias existen entre la una y la otra.

En segundo lugar, y de forma algo más extensa, he elegido seis ámbitos en los que se muestra de forma más clara las aportaciones de ambas y en los que se manifiesta también que sus conclusiones deberían ser especialmente relevantes para los que se dedican a la gestión de la educación. A veces se tienen en cuenta y otras veces no, lo que pone de relieve que la gestión política no se deriva de las conclusiones científicas sino que hay otros parámetros, también respetables, que 
proceden de compromisos, presiones sociales, acuerdos y orientaciones ideológicas y políticas que finalmente marcan la agenda de los cambios. Estos seis ámbitos son la infancia, la alfabetización inicial y la lectura, el estudio de las ciencias, la enseñanza de la música, la educación de los alumnos con necesidades especiales y la formación en valores y para una ciudadanía democrática. Terminaré con una última reflexión que es crucial para la educación: la tarea del maestro.

A lo largo de mi intervención trataré de defender tres tesis principales: la enorme capacidad de la educación para orientar, modificar y mejorar el curso del desarrollo; la importancia del contexto social y cultural de los alumnos en su desempeño educativo; y la especial relevancia que tienen en la acción educadora los valores que la sociedad y las comunidades educativas defienden y son capaces de llevar a la práctica.

Empecemos, como corresponde, por la primera parte: las relaciones entre la Psicología del Desarrollo y la Educación.

\section{LA PSICOLOGÍA DEL DESARROLLO}

La Psicología del desarrollo estudia principalmente los cambios y transformaciones del comportamiento humano a lo largo del tiempo. Su objetivo es describir, explicar e intervenir para orientar y mejorar el desarrollo desde el nacimiento, e incluso antes durante la gestación, hasta la muerte. Lejos queda, pues, aquella visión antigua en la que la evolución humana terminaba al final de la adolescencia.

Hay que destacar en primer lugar que existe un factor que tiene una indudable influencia en los procesos de desarrollo: la maduración del ser humano que marca los hitos principales de la evolución que son característicos de nuestra especie. Nacemos con un plan de vida básico contenido en nuestros genes: el reflejo de succión, el movimiento, la coordinación viso motora, el apego, la adquisición del lenguaje, la orientación, determinadas formas de conocimiento y de aprendizaje para la supervivencia, los cambios en la pubertad, el desarrollo sexual, la procreación y la protección de nuestros hijos y tantas otros cambios que marcan el desarrollo en la edad adulta y en la vejez. De alguna manera se pueden considerar estos cambios como normativos o comunes a la especie humana o, al menos, comunes para la mayoría de sus miembros que no sufren una alteración genética o ambiental que trastoque la previsible continuidad del desarrollo.

Pero la maduración o, dicho de otra forma, el despliegue de la dotación genética de cada persona, solo marca una dirección. En este proceso, es necesario tener en cuenta la influencia del ambiente, es decir, del conjunto de experiencias, de relaciones y de aprendizajes que la persona vive en una cultura determinada, en una familia concreta y en un sistema educativo específico y que van a concretar las posibilidades abiertas por la dotación genética.

Sin embargo, esta narración se torna ahora incompleta. La influencia del ambiente no opera solamente en las posibilidades abiertas por los genes de cada persona. 
Las investigaciones actuales ponen de manifiesto que las experiencias vividas por los seres humanos pueden incluso modificar la acción de nuestros genes. Creo que merece la pena detenernos en este punto pues es una reflexión clave para reforzar el enorme papel de la experiencia y, por tanto, de la educación, en el desarrollo de los humanos.

Nuestros genes no siguen una secuencia rígida e inflexible, sino que las influencias externas modulan la actividad de la dotación genética. Se podría apuntar la metáfora de que el ADN es como un DVD: almacena información pero necesita un reproductor de sonido. El reproductor de sonido estaría en ciertos mecanismos moleculares como los patrones de metilación o la modificación de las histonas que establecen cuándo un gen se manifiesta o cuando permanece oculto, desactivado. Actúan como aparatos de lectura y de transcripción de la información genética: pueden reproducirlo o inhibir la información contenida en el gen. Y lo más importante para nuestras disciplinas: el ambiente, la experiencia y, por tanto, la educación, pueden modificar estos factores de transcripción, es decir, pueden formar parte de la influencia de los genes en la conducta y en el psiquismo humano.

Me he detenido brevemente en este campo para resaltar no solo el papel del medio en el desarrollo, sino alguna de la claves neurobiológicas de esta influencia que empezamos a conocer. Ahora es el momento de orientar la reflexión sobre los diferentes tipos de ambientes para comprender mejor el desarrollo humano.

La cultura en la que se desarrollan las personas en un tiempo histórico determinado es el contexto más importante porque sus efectos operan en el resto de los entornos que influyen en la evolución de los humanos. La cultura está constituida por los valores, los hábitos, las actitudes, y los saberes acumulados a lo largo de los siglos y que la sociedad pretende transmitir a las nuevas generaciones. La escritura y la lectura de textos, el conocimiento científico, las expresiones artísticas y los sistemas de transmisión cultural reglamentados como la escuela son posiblemente los progresos de la humanidad que mayor repercusión están teniendo en el desarrollo y el aprendizaje de las nuevas generaciones. Luego hay que determinar cómo se accede a ellos, quiénes lo consiguen y en qué condiciones.

Los valores mayoritarios de una cultura tienen un efecto extraordinario en la vida de las personas. Pensemos en el respeto a la naturaleza por las culturas indígenas de la región, en donde los hombres estaban al servicio de la tierra frente al mensaje de las culturas judeo cristianas, en las que el hombre era el centro de la creación y la naturaleza estaba a su servicio. Pero también las pautas de crianza, el sentido de la vida, del buen vivir, de la felicidad y de la muerte, el significado del dolor, de la discapacidad, de las relaciones humanas, de la amistad y de la solidaridad. Todo ello afecta al desarrollo de los humanos y a la construcción de su identidad personal y social.

Los modelos, significados y contenidos culturales no operan normalmente de forma directa en los individuos sino que lo hacen a través de los grupos sociales en los que los niños y jóvenes se desenvuelven, principalmente la familia y la escuela, aunque no es posible olvidar los medios de comunicación y las nuevas 
tecnologías. Por ello el estudio de la influencia de la familia y de las prácticas escolares constituyen contextos imprescindibles para comprender la evolución de las conductas de los seres humanos.

Llegados a este punto, conviene regresar al inicio de nuestra reflexión y repasar nuestro hilo argumental. Señalamos que la psicología del desarrollo se plantea los cambios que se producen en la conducta a lo largo del tiempo, pero ahora hemos visto que también ha de tener en cuenta las diferencias culturales y sociales que intervienen en las transformaciones evolutivas. Hemos apuntado también que la psicología del desarrollo necesita para avanzar en la interpretación de los cambios de herramientas que proceden de otras disciplinas científicas, como la epigenética y las neurociencias vinculadas con el desarrollo, así como de otras estrechamente emparentadas con la evolución de los seres humanos: la sociología, la antropología cultural y la educación. Conocer el desarrollo humano de forma cabal exige una aproximación interdisciplinar que es ya inexcusable en los tiempos actuales.

Pero la psicología del desarrollo no pretende solamente describir y explicar los procesos de cambio que se producen con la edad a lo largo de toda la vida. Además, intenta adentrarse en una vertiente más técnica y aplicada: el análisis y la validación de los mecanismos de intervención más adecuados para favorecer el desarrollo. Ahora también es preciso conocer cómo actuar en los diferentes contextos en los que se produce el desarrollo, tanto en la esfera familiar, como en la social, en la cultural o en la educativa, y servirse de aquellas disciplinas que junto con las aportaciones propias de la psicología evolutiva, pueden proporcionar los conocimientos necesarios para el éxito en esta tarea. Entre todas ellas, los saberes procedentes del campo educativo ocupan un lugar de primer orden.

\section{LAS CIENCIAS DE LA EDUCACIÓN}

Por tanto, no parece posible avanzar en la interpretación del desarrollo y en su intervención si no tenemos en cuenta los conocimientos propios de las ciencias de la educación. No quiere esto decir que exista una dependencia de unos saberes frente a los otros, o que deban integrarse ambas aproximaciones científicas. Lo que pretendo defender es que unas y otras se necesitan mutuamente, cada una con sus propias concepciones teóricas y metodológicas.

Educar exige conocer al alumno y su evolución, pero también al profesor, a los contenidos que se pretende que los alumnos aprendan o al menos conozcan, a la familia, a los medios de comunicación, a las instituciones sociales y, sin duda, al entorno social y cultural en el que se desenvuelven los alumnos. Es preciso disponer, por tanto, de múltiples y variados conocimientos que se presentan organizados en diferentes disciplinas, en especial las didácticas específicas, la filosofía de la educación, la sociología de la educación y la psicología de la educación.

He dejado en el último lugar de la relación disciplinaria a la psicología de la educación pues, como señala César Coll, puede ser considerada una disciplina puente entre la psicología, en especial la psicología del desarrollo, y las ciencias 
educativas. Es en ella donde encontramos el principal nexo de unión entre los saberes de la evolución humana y de la psicología y los saberes de la educación.

La Psicología de la educación ha de construir su discurso y sus aplicaciones desde los modelos, métodos, conclusiones y preocupaciones que le ofrecen los conocimientos psicológicos y los conocimientos educativos. Pero a su vez, desde sus propios contenidos puede contribuir a completar los saberes de las ciencias psicológicas y de las ciencias educativas. Su riqueza se basa en su capacidad y plasticidad para recibir aportaciones de un lado y de otro. Su autonomía se asienta en las posibilidades para elaborar un cuerpo científico propio.

Pero la importancia que otorgamos a la Psicología de la Educación, que permite contrastar y profundizar en las teorías psicológicas, muy en especial en aquellas que proceden de la psicología del desarrollo, y en las teorías y modelos de las ciencias de la educación, no nos debe hacer olvidar la relevancia de otras dos disciplinas que también hemos de tener en cuenta en el continuo diálogo entre desarrollo y educación: la sociología de la educación y la filosofía de la educación.

Desde la sociología de la educación sabemos que la institución escolar, su currículo, sus planes y sus acciones están profundamente influidos por las características de la sociedad y por los modelos dominantes en ella. Y que incluso el acceso de los alumnos al conocimiento, a los títulos y a su promoción social posterior depende del capital cultural y social que la familia transmite. Y hay quien afirma que el sistema escolar busca, en última instancia, reproducir las desigualdades sociales existentes y mantener el dominio y el control del poder de los que lo han detectado desde siglos.

Y es de la mano de la filosofía de la educación donde surgen algunos de los interrogantes fundamentales que deben estar presentes en la reflexión educativa: ¿para qué educamos? ¿A qué tipo de persona y de sociedad aspiramos? ¿Cómo concretamos las esperanzas de una educación de mayor calidad y más equitativa para todos los alumnos? A partir de sus respuestas, es preciso abordar otras cuestiones más concretas pero no menos relevantes: ¿deben estudiar todos los alumnos juntos, sea cual sea su origen social y sus condiciones personales, o es mejor separarlos para supuestamente garantizar el éxito escolar? ¿Cuáles son las materias y contenidos más valiosos de la cultura que deben formar parte del currículo escolar y asegurar, por tanto, su presencia y su evaluación de forma destacada? ¿A qué etapas educativas y grupos de alumnos deben orientarse principalmente los recursos disponibles para la educación? Para cada uno de estos interrogantes hay respuestas que proceden de los análisis científicos, pero en el fondo y en última instancia es el modelo de sociedad al que se aspira y lo que se espera que alcancen los alumnos en las escuelas lo que orienta las decisiones finales.

\section{SEIS PRIORIDADES EDUCATIVAS}

Las relaciones entre desarrollo y educación, con su interfaz en la psicología de la educación, se manifiestan en la mayor parte de los ámbitos de estudio de cada una de estas disciplinas. Necesitaríamos algunos de los manuales disponibles, 
nada mejor que los de mis amigos y colegas Jesús Palacios y César Coll, para describir con profundidad estas interacciones. Prefiero, espero que Vds. también me lo agradezcan, centrarme en alguna de ellas. Y como les dije en mis primeras palabras, lo haré en torno a seis campos específicos: infancia, alfabetización, ciencia, música, educación especial y valores.

\section{LA INFANCIA TEMPRANA}

Los años iniciales de la vida del niño son cruciales para su desarrollo. No quiere esto decir que existan, como se pensaba en el pasado, períodos críticos en la evolución humana en los que las experiencias vividas marquen de forma irreversible el desarrollo posterior. Pero no cabe duda de que en la primera infancia se forman las estructuras básicas neurológicas, cognitivas, comunicativas, sociales y afectivas sobre las que se sustenta la evolución posterior.

El desarrollo cerebral se produce con una extraordinaria rapidez en los primeros años. El potencial neuronal se va progresivamente especializando y diferenciando a través de un innumerable número de conexiones sinápticas que aseguran los progresos de las funciones psicológicas en los seres humanos. En este proceso, el papel del ambiente en todas sus dimensiones -alimentación, salud, estimulación, afectos, comunicación- es fundamental.

La psicología del desarrollo pone de manifiesto los ejes básicos de la evolución en estas edades en todas las dimensiones y analiza los principales factores de este proceso. Nos habla de la maduración corporal, de la adquisición de destrezas motrices, de la inteligencia sensorio motora y simbólica, del juego, del apego y del desarrollo emocional, del progreso de la autonomía en la infancia, de la comunicación y del lenguaje, de la autoestima, del conocimiento y de las relaciones sociales y de los comienzos de la moralidad.

La psicología del desarrollo nos describe y explica, pues, multitud de cambios que se producen en breves períodos de tiempo. Pero nos dice también qué sucede y qué implicaciones tienen para el desarrollo futuro algunas experiencias que el niño vive. Analicemos, por ejemplo, las conductas de apego. Desde su nacimiento, el bebé expresa sus necesidades básicas o su necesidad de cuidado a través del llanto, lo que suele producir una respuesta de atención de la persona que le cuida, que le da satisfacción a su demanda. Poco a poco, el niño pequeño se va familiarizando con estas personas próximas, a las que asocia con la satisfacción de sus demandas y con su bienestar: las necesita y las prefiere a cualquier otra persona. Se encuentra, pues, apegado a ellas.

Las conductas de apego y el modelo interno de apego que el niño va construyendo pueden establecerse sobre una base tranquila y segura cuando las conductas de unos y de otros son próximas, predecibles, y confiables; o pueden, por el contrario, organizarse en torno a patrones inadecuados, desajustados e impredecibles. Hablamos entonces de apego inseguro, por no referirnos a aquellos modelos patológicos y por suerte minoritarios denominados trastornos reactivos de apego. 
Las conductas de apego satisfactorias y los más profundos modelos de apego son una garantía para el establecimiento futuro de relaciones seguras, confiadas y equilibradas. Lo contrario se produce cuando los vínculos del apego están distorsionados. No quiere esto decir que exista una relación necesaria entre las primeras conductas y las posteriores. Los apegos inseguros pueden modificarse en la dirección correcta cuando el niño encuentra personas de confianza que le ofrecen un afecto seguro, constante y predecible.

Ahora bien, haríamos mal en quedarnos solo con esta parte de la película como si solo existieran unas madres y unos padres más o menos afectuosos y unos hijos mejor o peor dispuestos hacia determinadas conductas de apego. La película completa es más compleja. Estos procesos e interacciones dependen en gran medida del contexto en los que el niño se desarrolla: su entorno social y cultural, la zona urbana o rural en la que habitan, los recursos familiares y las oportunidades educativas que le ofrecen, en gran medida dependientes del estatus económico, social y cultural de la familia. La pobreza y el nivel social y cultural de los padres condicionan la nutrición, la salud y las oportunidades de los hijos. A su vez, las políticas educativas incrementan o disminuyen las posibilidades de que los niños encuentren entornos educativos que amplíen sus experiencias y favorezcan su desarrollo y sus aprendizajes.

Entramos, de la mano del desarrollo y de la educación, en la esfera de la política y por tanto de los valores. El cuidado y la protección de la infancia debería ser una de las grandes prioridades de una sociedad y de un país, por su bien y por el bien de las futuras generaciones. Invertir en la infancia es, según los economistas, la mejor de las inversiones pues multiplica la tasa de retorno de cada sol invertido en una proporción tres veces superior a la inversión en la educación media y superior. Algunos estudios han comprobado que por cada dólar invertido en la infancia se revierten más de 16 dólares por la reducción de las tasas de abandono escolar, el progreso de los conocimientos y de las habilidades sociales, y la mejora de la integración social. Pero la inversión en la infancia debería proceder principalmente del sentido de la justicia social y de los derechos de los niños. Existe una obligación moral de todas las instituciones y de todos los ciudadanos de asegurar que los niños sean respetados como personas y protegidos por su especial vulnerabilidad.

Entre estos derechos están los de garantizar una condiciones de vida dignas y el acceso a entornos educativos enriquecedores y, por tanto, de calidad. La educación de los niños pequeños ha de ser integral e intersectorial, es decir, debe de abarcar la vertiente social, en donde hay que destacar el cuidado de la salud y de la nutrición, así como la vertiente educativa. En este último campo, los niños deben de tener acceso a experiencias educativas orientadas por educadores formados que les permitan convivir con otros niños, acceder a nuevas experiencias y potenciar su desarrollo integral.

La acción educadora en la infancia exige por tanto educadores competentes, tal vez los más competentes, pues deben dar respuesta de forma coordinada a cada uno de los ejes del desarrollo infantil: cognitivo, social, comunicativo, afectivo, 
moral y estético. Una tarea que exige al mismo tiempo una estrecha relación con la familia para multiplicar dicha actividad. De alguna manera, la educación en la infancia se convierte en una referencia permanente para el resto de las etapas educativas, más especializadas y con mayor riesgo de olvidarse de la educación integral de sus alumnos.

\section{ALFABETIZACIÓN INICIAL, CULTURA ESCRITA Y LECTURA}

Posiblemente no hay ámbito científico en donde las relaciones entre la psicología evolutivo-genética y las teorías de la educación se muestren con mayor intensidad que en el campo de la alfabetización y de la cultura escrita. ¿Cómo se aprende a leer y a escribir y como se enseñan estas actividades tan básicas como necesarias? Y contemplado desde otra perspectiva: ¿qué nos aportan los modelos de enseñanza y sus resultados para la comprensión de la construcción de la alfabetización y de la cultura escrita por parte de los niños?

Los avances en las últimas décadas han sido tan importantes como apasionantes han sido las discusiones y debates en relación con los métodos educativos más adecuados para enseñar a leer y a escribir a los niños, es decir, para conseguir que los niños accedan a la cultura escrita. Un debate que no ha estado alejado de los problemas sociales, de los códigos lingüísticos de las clases sociales y de la adecuación o inadecuación de la escuela a las diferencias sociales, culturales e individuales de los alumnos.

Las investigaciones sobre el desarrollo del lenguaje han puesto de manifiesto que las habilidades lingüísticas de los niños tienen un rápido desarrollo tanto en el dominio del vocabulario como en la competencia comunicativa. También los lingüistas han señalado que el lenguaje no se comprende sólo por su estructura sino que exige también conocer su utilización, es decir, su función pragmática. A su vez, los psicolingüistas han señalado la necesidad de que el lector conozca las relaciones entre el sistema visual y el sistema fonético, disponga de suficientes habilidades de codificación fonética y tenga una inicial competencia en el proceso de segmentación. Por su parte, los psicólogos cognitivos y del aprendizaje han destacado que existen requisitos previos para la alfabetización y el dominio de las habilidades lectoras como la capacidad de la memoria de trabajo y a largo plazo, la atención, el conocimiento del mundo y las habilidades metacognitivas, que en este caso son metalingüísticas. Esta última habilidad incluye al menos la comprensión de las relaciones sintácticas y contextuales y la percepción de que un texto posee una estructura determinada y transmite un tipo de mensaje.

Como se puede comprobar en este párrafo, ríos de tinta desde muy variadas disciplinas se han escrito para comprender cómo los niños progresan en sus procesos de alfabetización y en sus formas de manejar la cultura escrita. Estos avances exigen normalmente la presencia de un maestro que asegure una instrucción específica que permita a los alumnos adentrarse en el proceso de conciencia fonológica, de comprensión del significado de los textos escritos y de reflexión sobre la cultura escrita. La necesaria competencia metalingüística para adentrarse en la riqueza y 
profundidad de la cultura escrita necesita un guía adulto competente, es decir, un maestro, un maestro bien formado.

Pero en este ámbito de la alfabetización inicial, los conocimientos no proceden solamente de las investigaciones psicológicas y lingüísticas sino también de los resultados obtenidos por la aplicación en el aula de diferentes métodos didácticos. Dos han sido los métodos principales que han disputado la primacía en la segunda mitad del siglo XX: el denominado fonológico, que destaca la importancia de la descodificación y el aprendizaje de la correspondencia entre las letras y los sonidos; y el enfoque analítico o del significado, que resalta la importancia de la comprensión del texto en unidades más amplias que las letras o las palabras.

Junto a ellos, se han desarrollado también modelos constructivistas que ponen el acento en el protagonismo del aprendiz, en el enfoque integrado y contextualizado de la enseñanza y en la necesidad de que el alumno construya los significados de los textos a través de la reflexión sobre el uso del lenguaje en interacción con los otros. Desde esta perspectiva, no se niega la importancia de incorporar en el proceso de enseñanza el uso de unidades menores como la correspondencia de grafemas y fonemas, sino que se enfatiza como eje vertebrador de este proceso la incorporación de la reflexión sobre la lengua. Se reflexiona sobre la lengua mientras se utiliza en diferentes contextos y sistemas, es decir, en las situaciones en las que se lee y se escribe. Por ello, la escritura asume un papel relevante para pensar sobre la lengua y sobre las posibilidades de comunicación en un sistema escrito.

En la actualidad, estos diferentes enfoques metodológicos han ido convergiendo en modelos y prácticas educativas más integradoras si bien todavía los énfasis siguen siendo diferentes en sus formulaciones teóricas y en sus métodos aplicados, diferencias que son mucho más acusadas en la práctica pedagógica de cada uno de los profesores.

No todos los investigadores se han centrado en las ciencias psicológicas, lingüísticas y didácticas para conocer cómo los niños se adentran en la alfabetización y en la cultura escrita y cómo se les enseña. Algunos estudiosos en el campo de la sociolingüística -Basil Bernstein es una clara referencia en este camino- han puesto el acento en la influencia de la clase social en los códigos comunicativos que los niños aprenden en sus hogares y en la ventaja que tienen en la escuela aquellos que han adquirido códigos más elaborados pues son los que la institución escolar utiliza de forma preferente. La escuela, por tanto, a pesar de sus buenas intenciones, mantendría las desigualdades iniciales y apenas contribuiría a reducirlas.

Los cambios, pues, deberían proceder de la actualización de los métodos pedagógicos, de la adaptación de la escuela a las competencias iniciales de los alumnos y de programas que eleven el nivel cultural y la participación de las familias. En este proceso, la lectura puede convertirse en una estrategia prioritaria para conseguir ambos objetivos. Permítanme que me detenga en algunas consideraciones sobre la importancia de la lectura y sobre su capacidad para enriquecer la educación de los alumnos y del conjunto de la comunidad educativa. 
Leer es una de las actividades más completas, formativas y placenteras a la que podemos dedicar nuestro tiempo. La lectura puede ampliar nuestros conocimientos, transportarnos a otros mundos, ayudar a conocer a los otros y a nosotros mismos y hacernos vivir aventuras apasionantes en diferentes situaciones. La lectura tiene un enorme poder de fascinación. El aprendizaje de la lectura no tiene como objetivo único conseguir que los niños comprendan el significado de un texto escrito. La educación en la lectura debe ir más allá y lograr que los alumnos disfruten con cuentos, narraciones e historias.

El aprendizaje de los alumnos y, en consecuencia, el aprendizaje a través de la lectura, no debería quedar reducido a las relaciones profesor-alumno y al espacio del aula. El objetivo de la escuela no es solamente que los alumnos lean y que haya un profesor directamente responsable de la consecución de este objetivo. Es preciso que todos, profesores, padres y alumnos, se impliquen activamente en la tarea de despertar el gusto por la lectura y que consideren que la lectura es una estrategia primordial en el aprendizaje.

La escuela debería convertirse en un espacio de aprendizaje y de lectura para todos los que de una u otra forma participan en ella: profesores, alumnos y padres. El objetivo sería conseguir que los centros docentes se conviertan en comunidades de aprendizaje y, de forma más específica, en comunidades de lectores.

Para conseguir este objetivo, haría falta que la escuela valore la importancia de ayudar a los padres a que sean lectores y, además, a que sean lectores con sus hijos. Primero han de ser lectores. Es difícil que un niño sienta interés y aprecio por la lectura si no hay libros, ni revistas, ni periódicos en casa y sus padres apenas leen. Animar, facilitar, convencer a los padres de la importancia de que en la familia se valoren los libros y se dedique algún tiempo a la lectura es una tarea necesaria en la que no se debe escatimar esfuerzos desde la educación infantil. Asegurar el buen funcionamiento de la biblioteca escolar, cuidar las colecciones que pueden ser leídas por los padres, facilitar el préstamo de libros y la coordinación con otras bibliotecas públicas y propiciar encuentros de animación a la lectura son condiciones necesarias para que el objetivo de comprometer a los padres con la lectura pueda cumplirse. La biblioteca escolar se configura, desde este planteamiento, como un instrumento imprescindible para que la escuela llegue a convertirse en una comunidad de lectores.

Esta ambiciosa tarea exige que las Administraciones Educativas y las propias escuelas se impliquen activamente en su consecución. Es necesario que los alumnos dispongan de texto variados, que encuentren modelos adultos amantes de la lectura y que perciban que leer es la tarea privilegiada de la escuela. La lectura ha de ser una actividad cuidada y valorada por todos, con tiempos específicos diarios, en los que se combine la tranquilidad y el disfrute junto con el estímulo y la exigencia.

\section{LA FORMACIÓN CIENTÍFICA}

Los estudios sobre el pensamiento científico han sido un tema presente durante muchos años entre las preocupaciones de los psicólogos evolutivos y de los 
educadores. Los psicólogos han tratado principalmente sobre cómo se alcanza el razonamiento sobre la ciencia, la formulación y comprobación de hipótesis y el cambio conceptual. Por su parte, los científicos educativos se han planteado qué tipo de métodos y de estrategias didácticas favorecían el interés de los alumnos por la ciencia y contribuían de forma más eficaz en su aprendizaje.

Las propuestas de Inhelder y Piaget hace más de cincuenta años sobre la adquisición de las operaciones formales en la adolescencia están en el origen de buena parte de la investigación evolutiva sobre el pensamiento científico. Este tipo de operaciones está caracterizado, como es bien conocido, por su carácter hipotético deductivo y, en consecuencia, por la capacidad de combinar las variables presentes en un problema para determinar sus efectos. Es decir, el adolescente sería capaz de realizar deducciones a partir de determinadas premisas, de experimentar, de resolver problemas que requieren proporciones y probabilidades y también de razonar de forma inductiva, es decir, de transitar mentalmente de los datos a las conclusiones. Se ha avanzado en el desarrollo desde un sistema de operaciones concretas, que trabaja sobre objetos visibles, a otro sistema más elaborado que se adentra en el mundo de lo posible. Nos encontramos, pues, en el núcleo del razonamiento científico.

Las tesis de Inhelder y Piaget han sido discutidas y de alguna manera superadas en los años posteriores debido a la importancia que se otorga al contenido en el razonamiento lógico de los adolescentes y a la orientación de las nuevas investigaciones sobre aspectos específicos del razonamiento y no tanto a la búsqueda de sistemas generales de funcionamiento de la mente humana. Estas nuevas líneas de investigación han avanzado sobre todo en torno a tres ejes principales: la influencia de las ideas previas de los aprendices y el cambio conceptual; las diferencias entre expertos y principiantes; y las estrategias de razonamiento científico. Veamos brevemente cada uno de ellos antes de revisar qué aporta la didáctica de las ciencias al conocimiento del pensamiento científico.

Los niños intentan entender de forma intuitiva lo que sucede a su alrededor para obtener alguna explicación coherente. Por ello creen que un balón cae desde la altura después de darle un puntapié porque pierde el impulso inicial o piensan que la canica que sale de un tubo enrollado describe una línea curva. Existen, pues, en los niños un conjunto de creencia ingenuas que contradicen las leyes de la física. Lo mismo se puede decir de la biología, por ejemplo, cuando los niños no consideran que las zanahorias sean una planta.

Los alumnos no solo no conocen las leyes científicas sino que poseen un conjunto de concepciones erróneas que condicionan sus explicaciones de los fenómenos naturales. Además, estas concepciones no parece que sean solamente informaciones inexactas, sino que reflejan la existencia en los niños de un sistema de creencias incorrecto. La enseñanza de las ciencias no solo debe favorecer la adquisición de los conocimientos científicos, sino que ha de abordar al mismo tiempo unas ideas previas inadecuadas fuertemente arraigadas.

Parece, pues, que un método fructífero de enseñanza es el de enfrentarse a las creencias espontáneas o incorrectas que los alumnos llevan a clase y conseguir 
que modifiquen sus esquemas intuitivos para adentrarse en un nuevo sistema interpretativo. Las teorías o modelos del cambio conceptual se han convertido, por tanto, en un punto de encuentro enriquecedor entre los estudiosos del aprendizaje de las ciencias y los educadores en esta misma materia. De una parte, para que el cambio conceptual se produzca es necesario que los alumnos se sientan insatisfechos con sus creencias intuitivas, que las nuevas concepciones sean inteligibles y verosímiles y que permitan interpretar sucesos antes no considerados. Para que ello se produzca, es necesario que el profesor sea capaz de descubrir las ideas preconcebidas de los alumnos, les plantee un conflicto conceptual a través de la experimentación y de la discusión que les motive a buscar otras interpretaciones, y que finalmente información adicional refuerce los nuevos esquemas adquiridos.

Las diferencias entre los expertos y los principiantes también han contribuido a conocer cómo avanza el conocimiento científico. Las investigaciones realizadas concluyen que los expertos no solo tienen mayor conocimiento de los contenidos sino que organizan mejor la información, eligen estrategias más adecuadas al tipo de problema planteado y tienen una mejor comprensión de lo que significan las teorías y los conocimientos científicos. Estas conclusiones apuntan a la importancia de tener en cuenta en la enseñanza tanto el tratamiento de la información científica como la manera de incrementar la conciencia metacognitiva de los alumnos sobre cómo se accede al razonamiento científico.

Finalmente, los análisis sobre cómo afecta el desarrollo a los modos de resolución de problemas han abierto nuevas perspectivas sobre el conocimiento científico y la instrucción educativa. Las investigaciones se han orientado a conocer qué tipo de habilidades manifiestan los estudiantes en el razonamiento científico: formulación de hipótesis, diseño experimental, obtención de datos, comprobación de hipótesis, evaluación y producción de inferencias. La enseñanza guiada por el profesor para codificar mejor la información, manejar las hipótesis, controlar los resultados o facilitar inferencias en el marco de experimentos controlados que permiten la discusión y la confrontación de diferentes alternativas se ha manifestado como un buen esquema metodológico.

Sin embargo, también las ciencias educativas han avanzado en el tipo de instrucción que produce los mejores resultados y que contribuye a desarrollar el conocimiento científico. La experimentación constante, los procesos inductivos, la capacidad del profesor para suscitar dudas y abrir posibilidades de comprobación por parte de los alumnos, la participación y el debate y la relación entre la teoría y la práctica son estrategias metodológicas que se han mostrado especialmente fructíferas. Pero también existen múltiples interrogantes: ¿qué apoyo y control de los profesores es el óptimo? ¿Debe enseñarse a los alumnos las habilidades propias de cada dominio científico de forma concurrente o de forma separada? ¿Cómo incorporar en la enseñanza las características y los modelos de una investigación rigurosa, lo que suele suponer la incorporación de análisis estadísticos?

Llegados a este punto, es preciso cambiar de nuevo la perspectiva. La importancia de la formación científica y las estrategias para una mejor enseñanza no deriva solo de los progresos de la sociedad en este campo y de las aportaciones de la 
psicología y de la educación, sino también de los análisis sociales y de la necesaria educación en la ciudadanía de todos los alumnos.

Los estudios sociológicos ponen de manifiesto el escaso interés de los alumnos por la profesión científica y por la investigación. La encuesta realizada por el Observatorio Iberoamericano de Ciencia de la OEI a una muestra de estudiantes de secundaria de grandes núcleos urbanos indica que las preferencias de los jóvenes se orientan hacia estudios de ciencias sociales mientras que las vocaciones científicas sufrieron incluso disminuciones en las últimas décadas. Sólo el uno por ciento de los participantes en la encuesta manifestó que podía estar interesado por el trabajo científico. El análisis de los factores asociados a las preferencias de los alumnos indica el efecto de la enseñanza: cuanto más valoran los estudiantes cómo se imparte en la escuela las materias científicas, más atraídos se sienten por los estudios científicos. Pero la mayoría de los alumnos no valoran las clases de ciencias: seis de cada diez jóvenes señalan que las materias científicas son difíciles de entender; esa misma proporción dijo que nunca o casi nunca se preparan trabajos para ferias u olimpiadas científicas; cuatro de cada diez alumnos manifestaron que nunca o casi nunca se utilizan laboratorios o se hacen experimentos; y siete de cada diez señalaron que nunca o casi nunca había realizado viajes de estudios, visitas a laboratorios o a instituciones científicas. Estos datos podrían ser incluso más negativos si la muestra consultada se hubiera ampliado a las zonas rurales.

Este recelo y desinterés por la ciencia contrasta con las necesidades para el desarrollo económico de los países. Es muy difícil un crecimiento sostenido en Iberoamérica si no se produce al mismo tiempo una mayor preparación en las áreas científicas y tecnológicas, un aumento significativo de la inversión en ciencia y el acceso de un mayor número de jóvenes al campo de científico.

La sensibilización para el acceso a carreras científicas es una tarea importante de las escuelas. También lo es, sin duda, que la enseñanza de la ciencia sea atractiva y estimulante. Para ello, es preciso incorporar a lo largo del proceso de instrucción de los alumnos una constante referencia a la realidad social. La enseñanza de la ciencia debería incluir la valoración de sus efectos en la vida de la personas y de los grupos sociales y facilitar el debate de los alumnos sobre sus ventajas e inconvenientes o, mejor dicho, sobre los posibles riesgos que es preciso evitar.

Esta constante evaluación del impacto del progreso científico conecta con la última perspectiva a la que hicimos referencia: la educación ética y cívica. El conocimiento científico es un baluarte frente al dogmatismo y la manipulación, lo que puede conjugarse con las creencias religiosas o la visión espiritual de la vida. Cómo no aceptarlas y respetarlas al hablar en Perú, en donde las creencias ancestrales se hacen visibles e inmortales en el Machu Pichu.

No es posible ser un ciudadano activo, responsable y participativo en la sociedad del siglo XXI sin un conocimiento básico sobre los avances científicos y tecnológicos y su impacto en la vida de las personas y en la sociedad. Por ello, además, la formación científica para todos los alumnos debería ser una de las prioridades de la educación. 


\section{MÚSICA Y EDUCACIÓN}

Empezaré esta reflexión con dos citas. La primera es de un investigador, Antonio Damasio, en un libro publicado en 2010: Y el cerebro creó al hombre. La segunda, del ministro de Educación de Costa Rica, Leonardo Garnier, al defender su proyecto de Ética, estética y ciudadanía.

“En el nacimiento de artes como la música, la danza y la pintura, la gente posiblemente trató de comunicar a los demás información sobre amenazas y oportunidades, sobre la propia tristeza y alegría, y sobre lo que configuraba el comportamiento social...Y todo esto, antes incluso del maravilloso descubrimiento de que los seres humanos éramos capaces de producir palabras e hilvanarlas en oraciones, antes aún de que cayésemos en la cuenta de que no todos los sonidos sonaban igual. Los sonidos tenían tonos naturales y los tonos pudieron, a medida que pasaba el tiempo, relacionarse entre sí. Los acentos pudieron crear ritmos, y ciertos ritmos producían placer. La poesía pudo alzar el vuelo, y andando el tiempo la técnica puliría la práctica de la música y de la danza." (Antonio Damasio).

"Hace ya casi cuarenta años, cuando José Figueres impulsaba la creación de la Orquesta Sinfónica Nacional, la Sinfónica juvenil y la Infantil, se dio una discusión que tal vez hoy parecería bizarra: se alzaron las voces contra ese despilfarro de dinero: “¡lo que el país necesita era producir!” -se dijo. En lo mejor del debate, don Pepe pronunció una simple frase que acabó de una vez por todas con el debate: “¿Para qué tractores sin violines?" -dijo. Y entendimos". (Leonardo Garnier).

Durante muchos años, las artes y más en concreto la música han vivido un gran e injusto olvido en buena parte de los sistemas educativos. No es extraño que así haya sido por el enorme peso que las materias tradicionales ocupan en el currículo y por la orientación marcadamente cognitiva que tiene la educación en muchos países. Apenas hay lugar para las artes y, sorprendentemente, no se reivindica su papel en la formación de las nuevas generaciones, ni siquiera cuando se debate sobre las humanidades.

Pero no debería ser así. Desde la antigüedad clásica e incluso en épocas anteriores, la música y las artes han tenido una importancia central para el desarrollo del conocimiento. No es extraño por ello que los filósofos griegos consideraran a la música como la base de la educación o que establecieran estrechas relaciones entre los saberes matemáticos y los ritmos musicales. Pero aún más importante que la tradición histórica son los avances en la investigación de la psicología evolutiva, de la neurociencia y de la educación, que han subrayado la importancia de las artes como espacios que brindan la posibilidad de transformación de la dimensión humana, tanto en los ámbitos del conocimiento como en los afectivos, sociales y espirituales.

Los estudios sobre el desarrollo de las habilidades musicales y sobre la influencia de la música en el desarrollo se han multiplicado en las últimas décadas. El proceso de sensibilización musical comienza después del sexto mes de gestación. Posteriormente, en el primer año de vida, la comunicación no verbal con la madre 
o con el cuidador impulsa el desarrollo musical. Los cantos rítmicos, los tonos musicales y en especial las canciones de cuna arrullan al bebé y le tranquilizan a través de sencillas y repetitivas estructuras rítmicas. La música está impregnada de afecto y contribuye a crear una relación de confianza y de seguridad entre el adulto y el niño.

Con el paso del tiempo, la percepción de la música es más precisa y los niños empiezan a organizar los tonos y el ritmo musical de manera similar a como lo hacen las personas adultas. Los niños, que empezaron a balbucear y a emitir sonidos musicales a partir de los nueve meses, no consiguen producir diferentes tonos ni relacionar las letras con la música hasta su tercer año de vida. La habilidad musical, el canto y el aprendizaje de algún instrumento se desarrollan y adquieren posteriormente.

La mayor parte de los estudios realizados sobre los efectos de la música comprueban sus positivos efectos en el desarrollo de las personas. Sus beneficios se extienden a la alfabetización inicial y a la comprensión de textos, a la coordinación física, a la creatividad y a la autodisciplina, aunque en ocasiones estas consecuencias no puede generalizarse para todos los alumnos que participan en actividades musicales. La educación artística favorece también el desarrollo de la autoestima, la disposición para aprender, la capacidad de trabajar en equipo y el pensamiento abstracto.

Tal vez los principales beneficios se encuentran en el desarrollo de la sensibilidad, en la expresión emocional, en las relaciones sociales y en la creación de sentimientos de identidad personal y grupal. No cabe duda de que la música une a los adolescentes y crea potentes lazos emocionales. Un concierto con miles de asistentes produce en los participantes sensaciones únicas. Desde esta perspectiva, no parece acertado dejar la música fuera de las escuelas. Sería tan extraño como limitar la presencia de las nuevas tecnologías en la enseñanza.

Hay que reconocer, no obstante, que los retos en la educación artística, y la música dentro de ella, son muchos: el análisis de su situación y de sus posibilidades en el sistema educativo; la revisión de los currículos; el desarrollo de programas de formación docente; la exploración de nuevas metodologías y maneras de evaluar en el aprendizaje de las artes; el establecimiento de relaciones entre la educación artística y las nuevas tecnologías; y la incorporación del arte y de sus expresiones en las actividades habituales de las escuelas. Tal vez habría que iniciar nuevos caminos e incorporar la música y las artes en proyectos interdisciplinares de las escuelas que, junto con el trabajo específicamente disciplinar, convirtiera a la educación artística en uno de los ejes fundamentales para el desarrollo de los conocimientos, de la sensibilidad, de la convivencia, del trabajo en equipo y de la construcción de una ciudadanía multicultural.

No podemos olvidar que la música y las artes contribuyen también a la educación en valores. A través del desarrollo de la sensibilidad estética se favorece también el respeto hacia los otros, el conocimiento de nuevas formas y expresiones culturales y artísticas, el sentido de las diferencias y el valor del encuentro personal. Conocer, valorar y disfrutar de las expresiones artísticas de diferentes culturas 
fomenta en los jóvenes el reconocimiento y el respeto de la diversidad cultural y personal. La educación artística y las distintas expresiones musicales pueden convertirse en una estrategia clave para el desarrollo de los valores y de la ciudadanía democrática y multicultural.

Terminaré este apartado como lo inicié, con una breve cita, en este caso del poeta brasileño Ferreira Gullar: El arte existe porque la vida solamente no nos basta.

\section{LOS ALUMNOS CON NECESIDADES EDUCATIVAS ESPECIALES Y SU EDUCACIÓN}

El estudio del desarrollo de los alumnos con discapacidad ha supuesto a lo largo del tiempo un impulso constante tanto para la investigación evolutiva como para la reflexión educativa. El conocimiento de los cambios que viven los alumnos a lo largo del tiempo ha ayudado a constatar determinados invariantes en el desarrollo, así como a comprender qué factores explican las diferencias que se producen entre los que presentan alguna discapacidad y los que tienen una evolución sin alteraciones iniciales detectadas. La función de la vista, del acceso al lenguaje oral, de la movilidad, de la capacidad cognitiva o de las dificultades para la sistematización y las relaciones sociales han tenido una nueva perspectiva cuando se han estudiado los cambios evolutivos en niños con dificultades visuales, auditivas, motoras, mentales o sociales. El estudio del desarrollo de estas personas ofrece no solo orientaciones para su educación, sino análisis comparativos que mejoran la comprensión de la variabilidad y plasticidad del desarrollo humano.

Veamos por ejemplo el desarrollo de las personas sordas. El estudio de su evolución ha interesado a investigadores de diferentes especialidades y tradiciones científicas: los lingüistas han analizado las características de la lengua propia de los sordos, tantos años y en tantos lugares olvidada: la lengua de señas; los psicólogos han estudiado su desarrollo cognitivo, social y comunicativo y han comprobado la importancia de que los niños sordos adquieran desde pequeños la lengua que se codifica y expresa en un sistema manual para evitar el retraso que conlleva el aprendizaje de la lengua oral; a su vez, los antropólogos y sociólogos han observado las normas y relaciones de las personas sordas y el sentido de organizarse como un colectivo diferenciado en torno a una cultura y a una lengua propia; también los educadores han aportado una consistente reflexión sobre los sistemas de instrucción y los modos de relación entre la lengua de señas de los sordos, la lengua oral y los modos más idóneos para organizar los procesos de enseñanza y de aprendizaje.

Los estudios sobre la evolución de los niños sordos profundos indican que cuando adquieren desde edades tempranas una lengua no auditiva sino manual y visual como la de señas, reciben una educación de calidad en la que existe una comunicación bilingüe y hay una presencia de miembros de la comunidad sorda para favorecer su identidad personal, su desarrollo cognitivo es similar al de los niños oyentes. Hay que reconocer, no obstante, que la lengua oral, por su presencia masiva en la comunicación social y mediática, ofrece a los oyentes muchas más oportuni- 
dades de acceso a la información que la lengua de señas, por lo que la educación bilingüe es una garantía de respeto a la diferencia y de igualdad para los sordos.

Los estudios sobre la lengua de señas y sobre los procesos de aprendizaje de las personas sordas han ampliado nuestro conocimiento del lenguaje y de los sistemas de codificación ý de recuperación de la información de las personas que utilizan una lengua manual y visual. Además, la importancia de ofrecer a los alumnos sordos sistemas de comunicación adaptados a sus necesidades ha conducido a la construcción de diferentes modelos para favorecer su aprendizaje y su integración social en la escuela. La palabra complementada o Cued-Speech y los sistemas de comunicación bimodal son enfoques monolingües que complementan la utilización de la lengua oral. Frente a ellos, la incorporación de la lengua de señas junto con la oral supone un modelo bilingüe más respetuoso con las características propias de cada una de las lenguas.

También los estudios sobre la alfabetización inicial de los alumnos sordos, sobre la cultura escrita y sobre el efecto de los diferentes modelos comunicativos en su aprendizaje y en su desarrollo social han sido otros campos de interés en los que la investigación educativa ha permitido conocer mejor el desarrollo y el aprendizaje de los sordos y que también ha iluminado alguna claves antes olvidadas sobre el desarrollo de los oyentes. La educación de las personas con dificultades de aprendizaje en nuestra cultura oral por razón de su sordera nos ha ayudado enormemente a ser más justos con ellos y a conocer mejor cómo progresa el ser humano en contextos escolares.

A su vez, los alumnos autistas o, con mayor precisión, los alumnos afectados por un trastorno del espectro autista, plantean un reto enorme a la psicología y a la educación. A pesar de que llevamos más de medio siglo de investigaciones sobre su origen y su naturaleza, aún nos parece un misterio insondable su comportamiento, su opacidad y su impredictibilidad. Nos sorprende, nos desorienta y nos asusta que las personas autistas sean tan enigmáticas y que estén bloqueadas para la reciprocidad en las relaciones humanas. Como afirmó mi compañero y amigo Ángel Rivière, uno de nuestros grandes especialistas en este campo, posiblemente estas sensaciones que nos producen las personas autistas sean las mismas impresiones que nosotros mismos provocamos en ellos.

Las investigaciones sobre el espectro autista han desarrollado diferentes modelos interpretativos para explicar su comportamiento, predecir su desarrollar y diseñar estrategias adecuadas para su educación. Una de las más robustas ha sido la teoría de la mente, según la cual el trastorno autista consistiría en una grave alternación de la capacidad humana de atribuir mente, es decir, de ponerse en el lugar del otro, de imaginarse lo que piensa y lo que siente, de comprender sus intenciones y sus planes. Los temores y terrores de los autistas proceden en gran medida de su incapacidad de predecir el comportamiento y las intenciones de los otros: cualquier acción es impredecible y nunca saben qué sucederá después. Los autistas apenas desarrollan juegos simbólicos, ni entienden las metáforas, ni los engaños ni los mensajes con dobles intenciones. 
Los estudios sobre el autismo has continuado generando nuevas hipótesis. La teoría de la empatía y de la sistematización es una de las más recientes. Según sus postulados, los autistas tendrían un bajo nivel de empatía por sus dificultades sociales y de comunicación, y un alto nivel de sistematización, es decir, necesitarían organizar la realidad en la que viven con más número de reglas y con mayor orden tanto el campo sensorial y espacial como en el social y en el del comportamiento.

Los análisis y evaluaciones de la intervención pedagógica con los alumnos autistas han supuesto también un importante enriquecimiento sobre el desarrollo de los alumnos autistas y de sus posibilidades de cambio. Incluso han servido para poner en cuestión determinadas teorías o para reforzarlas. Los ambientes seguros, la utilización de diversos sistemas de comunicación, la enseñanza de habilidades sociales, la ayuda a los autistas para que descubran las intenciones de los otros y sus emociones, son estrategias coherentes con las interpretaciones psicológicas del espectro autista. También la música es una gran ayuda para ellos, pues su estructura y su ritmo metódico pueden ajustarse bien a la necesidad de orden de los autistas y ayudarles a relacionarse con otros y a sentirse mejor.

Es evidente por lo expuesto hasta ahora que los alumnos con discapacidad demandan una educación especializada. La calidad de esta enseñanza exige una enorme competencia de los maestros y una ampliación importante de los recursos destinados a ella. La respuesta educativa es aún más exigente si el objetivo es conseguir que estos alumnos participen con sus compañeros de la misma edad en la misma escuela. La educación inclusiva es un horizonte deseable y posible siempre que se cuiden las condiciones de la enseñanza y se sensibilice a la sociedad sobre la importancia de que todos los niños, o la mayoría de ellos, aprendan juntos.

La educación inclusiva se enfrenta a un reto enorme: garantizar el derecho de los alumnos a estar con sus compañeros y asegurar al mismo tiempo el derecho de los alumnos con discapacidad a aprender de acuerdo con sus posibilidades. Por tanto, no se trata de que estén en las escuelas normales aunque no aprendan, ni de que aprendan aunque estén separados. El compromiso con ambos derechos supone un fuerte compromiso con la transformación del sistema educativo hacia uno más flexible e integrador, en el que todos puedan avanzar sin que los más inteligentes se retrasen, ni los menos competentes se sientan marginados. Una tarea gigantesca que solo se mantiene si detrás de ella hay un aliento social y educativo basado en el valor de la educación y en los valores que la impulsan: el compromiso con una educación de calidad para todos los alumnos sin excepción, en la que todos perciban que aprender con los demás, sea cual sea su situación, es una factor de enriquecimiento y de preparación para una sociedad diversa y plural.

\section{LA EDUCACIÓN EN VALORES PARA UNA CIUDADANÍA DEMOCRÁTICA}

La opción ética que late en la apuesta por las escuelas inclusivas nos abre la puerta al último de nuestros temas: la educación en valores. El estudio de las normas morales ha sido un tema recurrente en las teorías psicológicas. El psicoanálisis 
destacó la formación del super-yo a partir de los tres años como proceso de interiorización de las normas morales y de las prohibiciones culturales. A su vez, las teorías conductistas del aprendizaje insistieron en la función del condicionamiento y de la observación de la conducta de modelos adultos para comprender el comportamiento moral de los niños. Pero han sido los estudios de Piaget y posteriormente de Kohlberg los que han marcado las perspectivas más fructíferas para comprender la conciencia moral.

La investigación de Piaget sobre el juicio moral hace ya ochenta años es una referencia imprescindible en los estudios sobre los cambios evolutivos en este campo. Además, el método utilizado, basado en la presentación de narraciones hipotéticas en las que pedía a los niños que valoraran la conducta de los protagonistas para conocer su criterio sobre las normas, la responsabilidad o el castigo, abrió un nuevo camino para adentrarse en los cambios que se producen en el razonamiento desde la infancia a la adolescencia. El cambio más importante que mostró la investigación piagetiana es el que se produce entre la moral heterónoma, basada en la aceptación de las reglas impuestas por el adulto, y la moral autónoma, asentada en la reflexión personal, en la cooperación y en la interpretación de las normas establecidas.

Los estudios de Kohlberg siguieron la senda piagetiana y buscaron establecer una pauta común y universal para el desarrollo moral estableciendo tres niveles: el preconvencional, dependiente de la autoridad; el convencional, cuyos criterios se basan en mantener la convivencia; y el postconvencional, cuya referencia son valores universales como los derechos humanos.

Estas formulaciones ya clásicas de la psicología evolutiva han sido modificadas y completadas en los años posteriores. De forma resumida se pueden señalar tres nuevas aportaciones: la influencia del contexto cultural, la función de las emociones en la conciencia moral, y las relaciones entre el criterio moral y el comportamiento.

La primera, tal vez la más importante, es la influencia del contexto cultural en la construcción del criterio moral. ¿La moralidad depende de principios universales y de cambios intelectuales cuyas estructuras básicas siguen una secuencia común en todas las personas, o, más bien, está enraizada en las normas y valores dominantes en cada cultura, que a su vez operan en la familia y en la escuela? Las investigaciones transculturales más recientes destacan la importancia de la propia cultura en la concepción de la moralidad, si bien debe admitirse al mismo tiempo que existen unos principios básicos en todas ellas, cuya expresión más aceptada es el reconocimiento del carácter universal de los derechos humanos.

No es posible desconocer, pues, la importancia de los valores dominantes de la cultura de un grupo humano en el juicio moral. Las relaciones de los humanos con la naturaleza es un buen ejemplo, como ya se apuntó anteriormente. Mientras que las culturas de tradición judeo cristiana sitúan al hombre en el centro de la creación, es la naturaleza el referente de la vida en las culturas originarias latinoamericanas. 
Por otra parte, hay culturas más orientadas al yo, a la libertad personal y a la autonomía, en donde la preocupación por los otros es expresión de una libre decisión altruista. Otras, en cambio, están orientadas hacia el nosotros, hacia la colectividad, la cooperación, la integración y el encuentro, en donde los valores del grupo son vividos como formas de realización personal. La educación no puede olvidarse de estas tradiciones y ha de ser capaz de favorecer un diálogo con los alumnos que facilite su autonomía moral en el marco de su cultura propia, sin olvidar las aportaciones de otras culturas y en la perspectiva de que interioricen el compromiso con los derechos humanos universales.

Un segundo campo de investigación es el que afecta a la función de las emociones en el desarrollo moral pues su dimensión cognitiva no debe conducir al olvido de los factores afectivos. Determinadas emociones tienen una especial relevancia en el comportamiento moral. La empatía, que pone de manifiesto la capacidad de compartir los sentimientos de los otros, es una de las más importantes pues favorece el altruismo, las conductas prosociales y las actitudes solidarias.

Finalmente, no son pocos los estudios que han tratado de analizar las relaciones entre el juicio moral y la acción. Aunque las investigaciones realizadas establecen una relación entre ambas dimensiones, no siempre se produce esta correspondencia. La razón fundamental se encuentra en que los valores, cuando se conectan con el comportamiento, han de ser aprendidos en la práctica, en las relaciones con los otros, especialmente con aquellos a los que se valora y se estima. De ahí la importancia de las relaciones entre maestros y alumnos y entre los propios alumnos. Por ello, de nuevo, la dimensión afectiva ha de tenerse en cuenta a la hora de establecer una relación más fuerte entre el razonamiento y la acción.

Los progresos en la investigación psicológica han sido revisados y completados con la experiencia educativa. La educación moral y ciudadana de los alumnos debería formar parte de los objetivos básicos de la escuela y tendría que ser una tarea del conjunto del profesorado y del propio funcionamiento de la escuela y no solo de un profesor en una hora determinada de docencia. Las escuelas deberían ser, de acuerdo con la propuesta de Kohlberg, comunidades justas en las que los jóvenes participaran en la gestión de las normas de convivencia y tuvieran un creciente protagonismo en las decisiones que se adoptaran. La educación ética y cívica se aprende en la acción, una acción reflexionada y dialogada cuyo efecto se multiplica en entornos ejemplares. Las escuelas deberían convertirse en un modelo de comunidad equitativa, participativa y solidaria. La educación en valores ha de concretarse en el funcionamiento de la propia escuela, donde la participación, el respeto mutuo, la tolerancia, la solidaridad con los más débiles y la responsabilidad personal y compartida sean objetivos colectivos. Por ello, la construcción de escuelas inclusivas, abiertas a todos los alumnos, son también modelos de referencia para una educación justa. 


\section{CONCLUSIÓN}

Es ya hora de concluir. Estamos aprendiendo de forma continua de las teorías, modelos, investigaciones y propuestas de intervención de la psicología del desarrollo y de las ciencias educativas, así como de sus disciplinas afines. Pero estos conocimientos serían insuficientes si no hubiera un colectivo de profesionales dispuestos a llevarlos a la práctica: los maestros. Ellos son indispensables en el quehacer educativo y de su formación, de la valoración social que perciben, del apoyo que reciben y de su compromiso con los alumnos, año tras año, depende el porvenir de las futuras generaciones y el progreso social, económico y cultural de los países.

La profesión docente conecta con lo más noble de la persona pues se orienta a enseñar a los otros, a facilitar sus aprendizajes en todas las dimensiones de la existencia y a promover el bienestar y el buen vivir de los alumnos que están bajo su cuidado. Por ello, la educación ha de asociarse con esperanza, dinamismo e ilusión. Desde esta perspectiva, no queda más remedio que admitir que la desmoralización de los docentes afecta al núcleo central de su profesión y que todas las acciones, individuales y colectivas, que se desarrollen para evitarla y para mantener y fortalecer el sentido de la acción educadora apuntan al factor clave de la calidad de la enseñanza. Nosotros también, todos nosotros, hemos de contarlo con nuestra palabra y de transmitirlo con nuestro ejemplo profesional. 